\title{
The Neuromuscular Effects of the Copenhagen Adductor Exercise: A Systematic Review
}

\author{
Morgan Schaber ${ }^{1}$, Zachary Guiser ${ }^{1}$, Logan Brauer ${ }^{1}$, Rebecca Jackson ${ }^{1}$, John Banyasz ${ }^{1}$, Ryan Miletti ${ }^{1}$, Amy Hassen-Miller ${ }^{2}$ \\ 1 Physical Therapy, Walsh University, 2 Physical Therapy, Walsh University (OH) \\ Keywords: adductor injuries, adductor strength, copenhagen adductor exercise, groin strain \\ https://doi.org/10.26603/001c.27975
}

\section{International Journal of Sports Physical Therapy}

Vol. 16, Issue 5, 2021

\section{Background}

Groin strains are one of the most common time-loss injuries in athletes. The Copenhagen Adductor Exercise (CAE) eccentrically strengthens the adductors and may function to prevent adductor strains, similar to the eccentric mechanism in which the Nordic Hamstrings exercise acts to prevent hamstring strains.

\section{Objective}

The purpose of this study was to systematically review the literature on the CAE and its effects on adductor muscle strength and muscle activity in athletes.

\section{Study Design}

Systematic Review

\section{Methods}

A systematic search of the literature was performed in the following databases: Pubmed; Medline (EBSCO); Sportdiscus; Scopus; Web of Science; CINAHL; Proquest; Cochrane Library; Physiotherapy Evidence Database (PEDro). Inclusion criteria consisted of 1) implements CAE, 2) includes athletes of any age participating in at least one sport, 3) study type is a cohort study or randomized control trial. Studies were excluded if they were not written in English or did not measure strength as an outcome. Data were extracted on eccentric hip adductor strength (EHAD), eccentric hip abductor strength (EHAB), EHAD:EHAB ratio, and electromyography (EMG) activity of the adductor muscles. Quality assessment was performed on all included studies using Quality Assessment Tool for Quantitative Studies.

\section{Results}

Five articles were identified for inclusion, four of which received a strong rating, and one a moderate rating on the Quality Assessment Tool for Quantitative Studies. The CAE significantly increased EHAD in four of the four studies that examined it; significantly increased EHAB and EHAD:EHAB in three of the three studies that examined them, and increased the EMG activity of the adductors in the dominant leg $108 \%$.

\section{Conclusion}

Overall, the CAE increases EHAD, EHAB, EHAD:EHAB, and EMG activity in the hip adductors in male soccer players. The increase in strength may reduce adductor muscle injuries, although more research needs to be done in this area to identify a clear

\footnotetext{
Corresponding author:

Amy Hassen-Miller

Physical Therapy Department, Walsh University, North Canton, OH, USA

ahassenmiller@walsh.edu

330.949.7581 (phone)

330.490 .7371 (fax)
} 
relationship between the CAE and groin injury prevention.

\section{Level of Evidence}

$1 b$

\section{INTRODUCTION}

Lower extremity muscle strains and injuries are commonplace in sports, especially those requiring the movement patterns of cutting, kicking, sprinting, and jumping. ${ }^{1}$ The hip adductors are able to produce torque in all three planes of motion. ${ }^{2}$ Furthermore, within the sagittal plane the adductor muscles are able to aid in production of both hip flexion and hip extension, depending on the starting position of the limb. ${ }^{3}$ The versatility of the hip adductors may help explain their relative susceptibility to injury and high injury recurrence rates. The prevalence of sports-related groin strains seems to be most common in hockey and soccer, however it is not limited to just these sports. 1,4

Studies following collegiate athletes in the NCAA report that adductor tears are one of the most prevalent injuries, ${ }^{4}$ and that most are a result of non-contact mechanisms. ${ }^{1}$ In sub-elite soccer, adductor injury to the dominant leg is the most prevalent injury. ${ }^{5}$ In the NHL, groin injury is also the most common injury, and has a high recurrence rate of $23.5 \%{ }^{6}$

Research performed on sub-elite soccer players has shown that having an adductor-related groin injury doubles the injury time compared to injuries not involving the adductor. ${ }^{5}$ Although recovery time is often described as being dependent on injury severity, research on sub-elite soccer players demonstrates that timelines may be more protracted than previously thought. Holmich et al found that $76 \%$ of groin injuries took greater than eight days to return to play. Of that $76 \%$ percent of injuries, $33 \%$ took greater than 28 days to recover, which illustrates the often prolonged nature of recovery. 5

While some research has shown that many adductor injuries require less than 1 week of time lost from play, the combination of high recurrence rates and number of games played in a week can lead to a significant number of games missed. ${ }^{1,4}$ In the NHL, it is estimated that the impact of groin/abdominal injury on each team is a game loss of 25 player games per year. ${ }^{6}$ An epidemiological study of professional soccer players has reported similar numbers, with an average $14.0+/-24.3$ days missed following adductor injury and an $18 \%$ reinjury rate. ${ }^{7}$

One of the most prevalent factors related to groin injuries is diminished adductor strength. High quality studies have reported an increased number of groin injuries occurring in individuals with decreased adductor strength. ${ }^{8-12}$ Additionally, a significant increased risk of groin injury is present when an athlete has had a previous groin injury as far as 20 months previously. 5

Researchers have assessed the relationship of hip adductor strength to hip abductor strength and imbalances between agonist/antagonist muscle groups. ${ }^{9,11,13}$ Sports that involve side-to-side cutting, striding, sudden change of direction and quick acceleration and deceleration are at a heightened risk of hip/groin injuries with a decreased level of hip adduction strength relative to the hip abduc- tors. ${ }^{9,11,13}$

With adductor weakness being prognostic of groin strains, it logically follows that exercise programs designed to strengthen the hip adductors may prevent groin strains. However, there is conflicting evidence for this. ${ }^{13-15}$ Studies without significant results reported poor compliance levels. ${ }^{16,17}$ When the adductor strengthening was performed with high compliance, injury rates decreased significantly. ${ }^{15}$ Even studies with statistically non-significant but clinically relevant results showed up to $31 \%$ reduction of adductor strains. ${ }^{14}$ This suggests that preventative effect is significant with compliance. This is further supported by the strong evidence for adductor strengthening in returning to play following a groin injury in research by Holmich et al. ${ }^{18}$

Therefore, the purpose of this study was to systematically review the literature on the CAE and its effects on adductor muscle strength and muscle activity in athletes.

\section{METHODS}

\section{REGISTRATION AND PROTOCOL}

This study was registered in the International Prospective Register of Systematic Reviews (PROSPERO) database under the ID: 178579.

\section{ELIGIBILITY CRITERIA}

The following criteria were required for inclusion: 1) implements $\mathrm{CAE}, 2$ ) includes athletes of any age participating in at least one sport, 3) study type is a cohort study or randomized control trial. Studies were excluded if they were not written in English or did not measure strength as an outcome. It is important to note that in the current research the term "football" refers to European football commonly known as soccer in the US. The term soccer will be used to describe European football throughout this manuscript. The CAE is defined as an exercise in which the participant assumes a side plank position, with superior lower extremity held by a partner. The participant lowers the free lower extremity to the ground, producing pelvic on femoral abduction on the supported extremity, then raises it to return to the start position, producing pelvic on femoral concentric adduction on the supported extremity. ${ }^{17}$ (Figure 1) Based on this exercise, the adductor strengthening program was developed and studied. ${ }^{19}$

\section{SEARCH STRATEGY, DATABASES UTILIZED, AND STUDY SELECTION}

The search strategy for each database is provided in Appendix 1. The following databases were searched: Pubmed; Medline (EBSCO); Sportdiscus; Scopus; Web of Science; CINAHL; Proquest; Cochrane Library; Physiotherapy Evidence Database (PEDro). All studies identified in the search were obtained and duplicates removed. Two researchers in- 
dependently reviewed titles and abstracts for inclusion criteria. Inclusion criteria consisted of 1) implements CAE, 2) includes athletes of any age participating in at least one sport, 3) study type is a cohort study or randomized control trial. Studies were excluded if they were not written in English or did not measure strength as an outcome Consensus between researchers was reached if there was initial disagreement. Full text articles identified through the title and abstract search were screened by two researchers; consensus was reached after any disagreement. The initial search was conducted April, 2020. Follow up searches were completed September 2020 and February 2021.

\section{DATA EXTRACTION AND ANALYSIS}

Each article was individually reviewed by two reviewers; consensus was reached following any initial disagreement. Author and date, study type, sample size, age, sport, intervention, independent variable, control, and outcome measures were extracted. The following outcome measures were extracted from the articles: eccentric hip adductor strength (EHAD), eccentric hip abductor strength (EHAB), EHAD:EHAB ratio, delayed onset muscle soreness (DOMS), electromyography (EMG) activity, knee flexor strength, sprint speed, and Rate of Perceived Exertion (RPE). Data analyzed in this systematic review were EHAD strength, EHAB strength, EHAD:EHAB ratio, and EMG activity.

\section{QUALITY ASSESSMENT}

Quality assessment was performed independently by three reviewers. Each reviewer assessed the articles with the Quality Assessment Tool for Quantitative Studies, which was developed by the Effective Public Health Practice project. $^{20}$ The studies were assessed independently prior to discussion and consensus regarding strength of the study. The Quality Assessment Tool rates studies based on selection bias, study design, confounders, blinding, data collection methods, withdrawals and drop-outs, intervention integrity, and analysis, culminating in a global rating of strong, moderate or weak based on the culmination of category ratings.

\section{RESULTS}

\section{STUDY SELECTION}

The results of the search criteria produced 8,880 titles, which were reviewed for applicability. After title assessment and abstracts were screened, 53 were deemed appropriate for full-text review. The agreement between the two authors for the full text review was $\mathrm{k}=.89$ (almost perfect agreement) for which full text articles were selected for inclusion. Discrepancies were decided through discussion and a consensus was reached. Five full-text articles were selected after full evaluation and included in the systematic review. (Figure 2)

\section{QUALITY ASSESSMENT}

The Quality Assessment Tool for Qualitative Studies has been shown to have fair inter - rater agreement for individ-

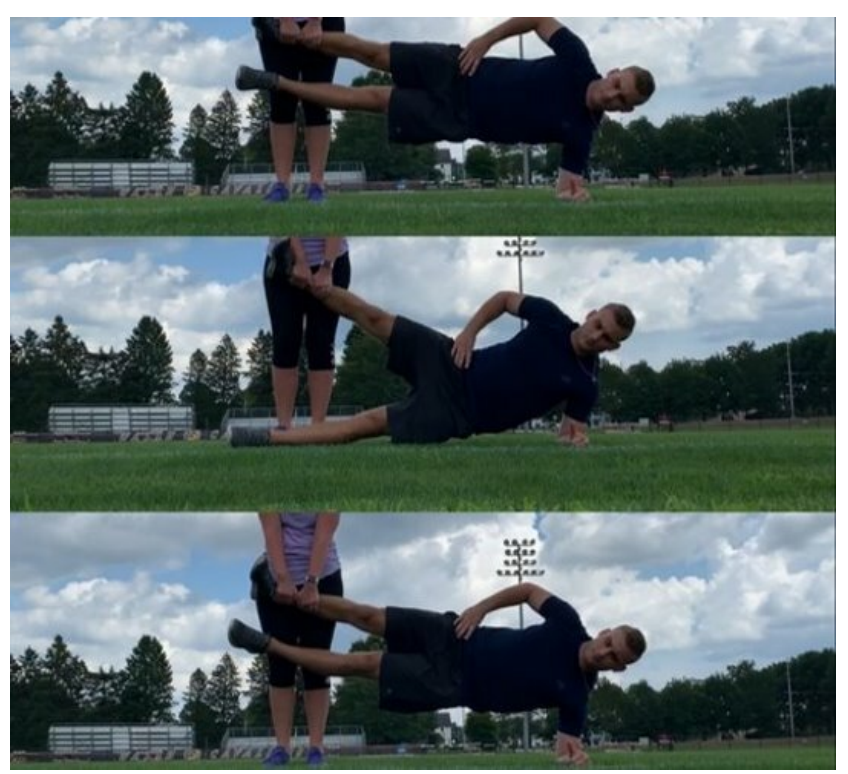

Figure 1. The Copenhagen adductor exercise. Top image shows the starting position, middle image shows the eccentric pelvic on femoral abduction phase, bottom image shows the concentric pelvic on femoral adduction phase.

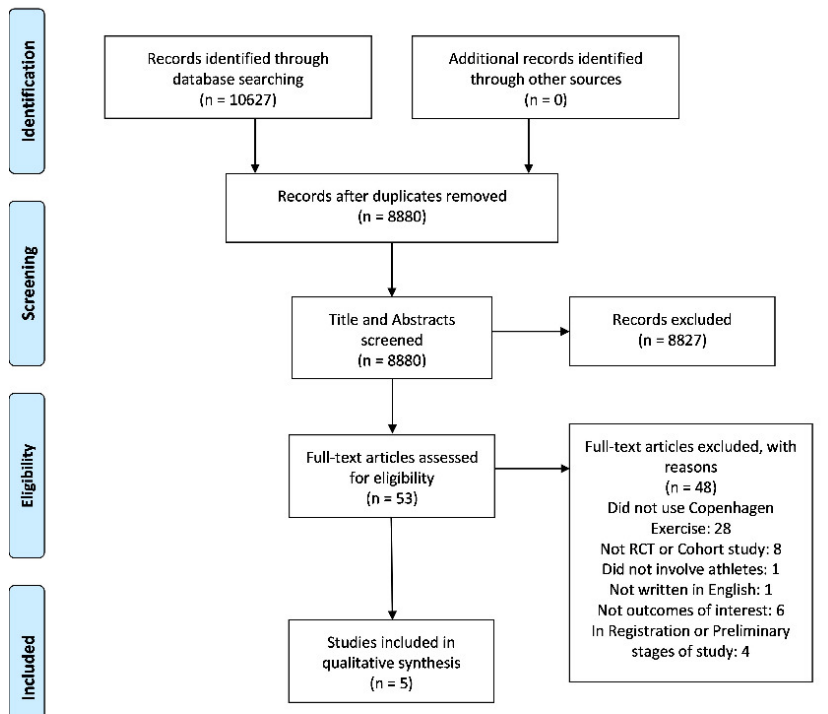

Figure 2.

$\mathrm{n}=$ number; $\mathrm{RCT}=$ randomized control trial

ual domains and excellent agreement for the final grade. ${ }^{20}$ Four of the studies were rated as strong, while one of the studies was rated as moderate using the tool. The agreement between authors for the quality assessment "Global Rating” was k=1.0. Details can be found in Table 1 .

\section{STUDY CHARACTERISTICS}

Three studies were randomized controlled trials and two were cohort studies. All five studies were performed on male 
Table 1. Quality Assessment Analysis

\begin{tabular}{|c|c|c|c|c|c|c|c|}
\hline Study & $\begin{array}{l}\text { Selection } \\
\text { Bias }\end{array}$ & $\begin{array}{l}\text { Study } \\
\text { Design }\end{array}$ & Confounders & Blinding & $\begin{array}{l}\text { Data } \\
\text { Collection } \\
\text { Methods }\end{array}$ & $\begin{array}{l}\text { Withdrawals } \\
\text { and Drop- } \\
\text { outs }\end{array}$ & $\begin{array}{l}\text { Global } \\
\text { Rating }\end{array}$ \\
\hline $\begin{array}{l}\text { Harøy, J } \\
\text { et al., } \\
2017^{19}\end{array}$ & Strong & Strong & Strong & Strong & Strong & Moderate & Strong \\
\hline $\begin{array}{l}\text { Ishoi, Let } \\
\text { al., } \\
2016^{21}\end{array}$ & Moderate & Strong & Strong & Moderate & Strong & Strong & Strong \\
\hline $\begin{array}{l}\text { Polglass, } \\
\text { G et al., } \\
2019^{22}\end{array}$ & Moderate & Moderate & Strong & Strong & Strong & Moderate & Strong \\
\hline $\begin{array}{c}\text { Kohavi, B } \\
\text { et al., } \\
2018^{23}\end{array}$ & Strong & Strong & Strong & Moderate & Strong & Moderate & Strong \\
\hline $\begin{array}{l}\text { Serner, A } \\
\text { et al., } \\
2014^{17}\end{array}$ & Strong & Weak & Strong & Strong & Strong & Strong & Moderate \\
\hline
\end{tabular}

Methodological quality is rated (guidance provided) for the following areas: selection bias, study design, cofounders, blinding, data collection methods, withdrawals and dropouts, intervention integrity, and analysis.

Strong - no weak ratings given

Moderate - one weak rating

Weak - two or more weak ratings

soccer players. Number of participants and mean age can be found in Table 2. Four studies had hip adduction strength as the primary outcome measure (measured in a side-lying break test according to Thorborg's protocol ${ }^{24}$ using a handheld dynamometer), while one study had EMG activity as the primary outcome measure. All five studies used the CAE, but one study used a modified progression to build up to the CAE. Study and intervention details can be found in Table 2.

EMG activity was measured through bipolar disposable silver/silver chloride surface electrodes placed parallel to muscle fibers with two centimeters between electrodes to avoid unstable recordings. To confirm correct placement of electrodes, a manual muscle test was performed while monitoring EMG. EMG activity was measured in the adductor longus, ${ }^{25,26}$ gluteus medius, ${ }^{25-28}$ rectus abdominis, ${ }^{29}$ and external abdominal oblique. ${ }^{30,31}$

\section{STRENGTH ASSESSMENT}

Four of the studies included maximal eccentric hip adduction strength (EHAD) as an outcome measure. All studies found a significant increase in EHAD in the groups using the CAE. Three of the four studies also included EHAB and EHAD:EHAB ratio, and all studies found significant increases in these additional variables for the groups using the CAE. Results can be found in Table 3 .

Haroy et al randomized 45 male soccer players into two groups: one group performed the FIFA 11+ warm up pro- gram (which includes the Nordic hamstring exercise); the other group performed the FIFA 11+ but replaced the Nordic hamstring exercise with CAE. Both groups performed the intervention three times a week for eight weeks. Significant EHAD strength was found in the group performing the CAE. ${ }^{16}$ (Table 3)

Ishoi et al conducted a cluster randomized trial where they recruited two soccer teams to participate in an eight week training program twice a week. One team was designated as the control and was assigned to continue training as usual. The other team was assigned as the intervention group and participated in a progressive training program using the CAE in addition to usual training. The CAE group demonstrated significant increases in EHAD, EHAB and EHAD:EHAB. ${ }^{21}$ (Table 3)

Kohavi et al randomized 42 soccer players into a CAE, sliding hip (SH), or a control group. The SH exercise is described as, "(t)he athlete stand(s) with both legs on a plastic sliding pad, with trunk, hips, and knees straight, and hands placed in front of the chest on a stable supporting bar. Both legs are abducted, and the center of gravity moves downward as much as controllably possible. After reaching the maximal distance and keeping the same position for two seconds, the legs are adducted, sliding back to the starting position.” The CAE and SH group performed their respective exercises two sessions a week for eight weeks. The control group performed a time matched protocol of hip mobility exercises. Both the CAE and $\mathrm{SH}$ groups experienced significant increases in EHAD, EHAB and EHAD:EHAB. ${ }^{23}$ (Table 3) 
Table 2. Included Study Demographic Information

\begin{tabular}{|c|c|c|c|c|c|c|c|}
\hline Study & Intervention Details & $\begin{array}{l}\text { Study } \\
\text { Design }\end{array}$ & $\begin{array}{l}\text { Participants } \\
\text { (n) }\end{array}$ & Age (Years) & Gender & Sport & $\begin{array}{l}\text { Outcome } \\
\text { Measures }\end{array}$ \\
\hline $\begin{array}{l}\text { Haroy, J } \\
\text { et al., } \\
2017^{19}\end{array}$ & $\begin{array}{l}\text { CA performed on both sides compared to Nordic Hamstring. Intervention performed } \\
3 \times \text { per week for } 8 \text { weeks with } 1 \text { set per side, progressing from 3-5 reps to } 12-15 \text { reps } \\
\text { from beginner to advanced athletes. }\end{array}$ & RCT & 33 & $\begin{array}{l}\text { Control } \\
\text { Group - } \\
16.9 \pm 1.0 \\
\text { Intervention } \\
\text { Group- 16.7 } \\
\pm 0.9\end{array}$ & $\begin{array}{l}100 \% \\
\text { Male }\end{array}$ & Soccer & EHAD \\
\hline $\begin{array}{l}\text { Ishoi, L } \\
\text { et al., } \\
2016^{21}\end{array}$ & $\begin{array}{l}\text { CA performed both sides compared to control group with no intervention. } \\
\text { Intervention performed } 2 \times \text { per week for } 8 \text { weeks, progressing from } 2 \text { sets of } 6 \text { reps } \\
\text { per side each session to } 3 \text { sets of } 15 \text { reps per side each session }\end{array}$ & $\begin{array}{l}\text { Cluster } \\
\text { RCT }\end{array}$ & 20 & $\begin{array}{l}\text { Control - } \\
17.4 \\
(17-18)^{*} \\
\text { Intervention } \\
-17.3 \\
(17-18)^{*}\end{array}$ & $\begin{array}{l}100 \% \\
\text { Male }\end{array}$ & Soccer & $\begin{array}{l}\text { EHAD } \\
\text { EHAB } \\
\text { EHAD:EHAB }\end{array}$ \\
\hline $\begin{array}{l}\text { Polglass, } \\
\text { G et al., } \\
2019^{22}\end{array}$ & $\begin{array}{l}\text { Modified Progressive CA (MPCA) with no comparison group. MPCA consisted of } 6 \\
\text { levels, ranging from an assisted isometric adduction to a full CA exercise. Intervention } \\
\text { was performed } 2 x \text { per week for } 8 \text { weeks, progressing from } 2 \text { sets of } 6 \text { reps per side to } \\
3 \text { sets of } 10 \text { reps per side. }\end{array}$ & Cohort & 17 & $\begin{array}{l}27.4 \\
(20-35)^{*}\end{array}$ & $\begin{array}{l}100 \% \\
\text { Male }\end{array}$ & Soccer & $\begin{array}{l}\text { EHAD } \\
\text { EHAB } \\
\text { EHAD:EHAB }\end{array}$ \\
\hline $\begin{array}{l}\text { Kohavi, } \\
\text { B et al., } \\
2018^{23}\end{array}$ & $\begin{array}{l}\text { CA compared to sliding hip (SH) exercises and control group with active mobilization. } \\
\text { Intervention performed } 2 \times \text { per week for } 8 \text { weeks, progressing from } 2 \text { sets of } 6 \text { reps } \\
\text { per side to } 4 \text { sets of } 9 \text { reps per side. }\end{array}$ & $\begin{array}{l}\text { Prospective } \\
\mathrm{RCT}\end{array}$ & 42 & $17.5 \pm 1.1$ & $\begin{array}{l}100 \% \\
\text { Male }\end{array}$ & Soccer & $\begin{array}{l}\text { EHAD } \\
\text { EHAB } \\
\text { EHAD:EHAB }\end{array}$ \\
\hline $\begin{array}{l}\text { Serner, } \\
\text { A et al., } \\
2014^{17}\end{array}$ & Examined the EMG activity of 6 different adductor exercises. & Cohort & 35 & $21.4 \pm 3.3$ & $\begin{array}{l}100 \% \\
\text { Male }\end{array}$ & Soccer & EMG activity \\
\hline
\end{tabular}

" = age range; $\mathrm{EHAD}$ = eccentric hip adduction strength; EHAB = eccentric hip abduction strength; EMG=electromyography 
Table 3. EHAD strength, EHAB strength, and EMG ratio from Copenhagen Adductor Exercise

\begin{tabular}{|c|c|c|c|c|c|c|c|c|}
\hline \multirow[b]{2}{*}{ Study } & \multicolumn{4}{|l|}{ Strength } & \multicolumn{4}{|l|}{ EMG } \\
\hline & $\operatorname{Leg}(s)$ & EHAD Strength & EHAB Strength & EHAD:EHAB Ratio & $\begin{array}{l}\text { Adductor } \\
\text { Longus } \\
\text { (\% MVIC) }\end{array}$ & $\begin{array}{l}\text { Gluteus } \\
\text { Medius } \\
\text { (\% } \\
\text { MVIC) }\end{array}$ & $\begin{array}{l}\text { External } \\
\text { Abdominal } \\
\text { Oblique (\% } \\
\text { MVIC) }\end{array}$ & $\begin{array}{l}\text { Rectus } \\
\text { Abdominis } \\
\text { (\% MVIC) }\end{array}$ \\
\hline \multirow{6}{*}{$\begin{array}{l}\text { Harøy, J } \\
\text { et al., } \\
2017^{19}\end{array}$} & \multirow[b]{2}{*}{ Cumulative } & $8.0 \%$ increase & \multirow[b]{2}{*}{-} & \multirow[b]{2}{*}{-} & \multirow[b]{2}{*}{ - } & \multirow[b]{2}{*}{ - } & \multirow[b]{2}{*}{-} & \multirow[b]{2}{*}{-} \\
\hline & & $\begin{array}{l}(3.25 \pm 0.62 \text { to } 3.51 \pm 0.63 \\
\mathrm{Nm} / \mathrm{kg}) ;(\mathrm{p}<0.001) ;(\mathrm{d}= \\
0.60)\end{array}$ & & & & & & \\
\hline & \multirow[b]{2}{*}{ Nondominant } & $8.5 \%$ increase & \multirow[b]{2}{*}{-} & \multirow[b]{2}{*}{-} & \multirow[b]{2}{*}{-} & \multirow[b]{2}{*}{-} & \multirow[b]{2}{*}{ - } & \multirow[b]{2}{*}{-} \\
\hline & & $\begin{array}{l}(3.22 \pm 0.68 \text { to } 3.49 \pm 0.69 \\
\mathrm{Nm} / \mathrm{kg}) ;(p<0.001)\end{array}$ & & & & & & \\
\hline & \multirow[b]{2}{*}{ Dominant } & $7.4 \%$ increase & \multirow[b]{2}{*}{-} & \multirow[b]{2}{*}{ - } & \multirow[b]{2}{*}{ - } & \multirow[b]{2}{*}{-} & \multirow[b]{2}{*}{ - } & \multirow[b]{2}{*}{-} \\
\hline & & $\begin{array}{l}(3.29 \pm 0.57 \text { to } 3.53 \pm 0.58 \\
\mathrm{Nm} / \mathrm{kg})(\mathbf{p}=0.02)\end{array}$ & & & & & & \\
\hline \multirow{2}{*}{$\begin{array}{l}\text { Ishoi, L } \\
\text { et al., } \\
2016^{21}\end{array}$} & \multirow[b]{2}{*}{ Cumulative } & $35.7 \%$ increase & $20.3 \%$ increase & $12.3 \%$ increase & \multirow[b]{2}{*}{-} & \multirow[b]{2}{*}{-} & \multirow[b]{2}{*}{-} & \multirow[b]{2}{*}{-} \\
\hline & & $\begin{array}{l}(2.71 \pm 0.48 \text { to } 3.67 \pm 0.38 \\
\mathrm{Nm} / \mathrm{kg}) ;(p<0.001) ;(d=2.2,) \\
95 \% \mathrm{Cl}(25.83 \%, 45.39 \%)\end{array}$ & $\begin{array}{l}(2.27 \pm 0.41 \text { to } 2.74 \pm 0.41 \\
\mathrm{Nm} / \mathrm{kg}) ;(\mathrm{p}<0.001) ;(\mathrm{d}=1.1) \\
95 \% \mathrm{Cl}(12.78 \%, 28.19 \%)\end{array}$ & $\begin{array}{l}(1.22 \pm 0.28 \text { to } 1.37 \pm \\
0.23) ;(p=0.019)(d=0.6) ; \\
95 \% \mathrm{Cl}(2.46 \%, 21.31 \%)\end{array}$ & & & & \\
\hline \multirow{4}{*}{$\begin{array}{l}\text { Polglass, } \\
\text { G et al., } \\
2019^{22}\end{array}$} & \multirow[b]{2}{*}{ Right } & $25 \%$ increase & $13 \%$ increase & $10 \%$ increase & \multirow[b]{2}{*}{-} & \multirow[b]{2}{*}{-} & & \\
\hline & & $\begin{array}{l}(3.46( \pm 0.49) \text { to } 4.32( \pm 0.86)) ; \\
(p<0.01)\end{array}$ & $\begin{array}{l}(3.08( \pm 0.55)-3.5( \pm 0.67)) ;(p \\
<0.01)\end{array}$ & $\begin{array}{l}(1.12( \pm 0.51) \text { to } 1.24 \\
( \pm 0.75)) ;(p<0.01)\end{array}$ & & & - & - \\
\hline & & $24 \%$ increase & $10 \%$ increase & $12 \%$ increase & & & & \\
\hline & Left & $\begin{array}{l}(3.55( \pm 0.53) \text { to } 4.40( \pm 0.64)) \\
(p<0.01)\end{array}$ & $\begin{array}{l}(3.17( \pm 0.43) \text { to } 3.5( \pm 0.64)) \\
(\mathbf{p}<0.01)\end{array}$ & $\begin{array}{l}(1.12( \pm 0.49) \text { to } 1.26 \\
( \pm 0.65)) ;(p<0.01)\end{array}$ & - & - & - & - \\
\hline & & $45.8 \%$ increase & $18.5 \%$ increase & $23.6 \%$ increase & & & & \\
\hline $\begin{array}{l}\text { Kohavi, } \\
\text { B et al., }\end{array}$ & Right & $\begin{array}{l}(0.84 \pm 0.38 \text { to } 4.11 \pm 0.76 \\
\mathrm{Nm} / \mathrm{kg}) ;(\mathrm{p}<0.001) ;(\mathrm{d}= \\
2.11)\end{array}$ & $\begin{array}{l}(2.57 \pm 0.36 \text { to } 3 \pm 0.36 \mathrm{Nm} / \\
\mathrm{kg}) ;(p<0.01) ;(d=1.18)\end{array}$ & $\begin{array}{l}(1.12 \pm 0.18 \text { to } 1.38 \pm \\
0.26) ;(p<0.001) ;(d= \\
0.84)\end{array}$ & - & - & - & - \\
\hline $2018^{23}$ & & $49.4 \%$ increase & $15.1 \%$ increase & $31.5 \%$ increase & & & & \\
\hline & Left & $\begin{array}{l}(2.76 \pm 0.46 \text { to } 4.13 \pm 0.91 \\
\mathrm{Nm} / \mathrm{kg}) ;(p<0.001) ;(d=1.9)\end{array}$ & $\begin{array}{l}(2.59 \pm 0.28 \text { to } 2.96 \pm 0.28 \\
\mathrm{Nm} / \mathrm{kg})(\mathbf{p}=0.01) ;(\mathrm{d}=1.32)\end{array}$ & $\begin{array}{l}(1.07 \pm 0.21 \text { to } 1.4 \pm 0.35) ; \\
(p=0.001) ;(d=1.14)\end{array}$ & - & - & - & - \\
\hline $\begin{array}{l}\text { Serner, } \\
\text { A et al., }\end{array}$ & Dominant & - & - & - & - & $20 \pm 3$ & $29 \pm 3$ & $19 \pm 3$ \\
\hline
\end{tabular}




\begin{tabular}{|c|c|c|c|c|c|c|c|c|}
\hline \multirow[b]{2}{*}{ Study } & \multicolumn{4}{|l|}{ Strength } & \multicolumn{4}{|l|}{ EMG } \\
\hline & $\operatorname{Leg}(s)$ & EHAD Strength & EHAB Strength & EHAD:EHAB Ratio & $\begin{array}{l}\text { Adductor } \\
\text { Longus } \\
\text { (\% MVIC) }\end{array}$ & $\begin{array}{l}\text { Gluteus } \\
\text { Medius } \\
\text { (\% } \\
\text { MVIC) }\end{array}$ & $\begin{array}{l}\text { External } \\
\text { Abdominal } \\
\text { Oblique (\% } \\
\text { MVIC) }\end{array}$ & $\begin{array}{l}\text { Rectus } \\
\text { Abdominis } \\
\text { (\% MVIC) }\end{array}$ \\
\hline $2014^{17}$ & $\begin{array}{l}\text { Non- } \\
\text { Dominant }\end{array}$ & - & - & - & - & $48 \pm 3$ & $36 \pm 3$ & $40 \pm 3$ \\
\hline
\end{tabular}

EHAD = eccentric hip adduction strength; $\mathrm{EHAB}=$ eccentric hip abduction strength; $\mathrm{MVIC}=$ maximal voluntary isometric contraction; EMG = electromyography; $\mathrm{CA}=$ Copenhagen adductor exercise. Bolded p=values indicate statistically significant differences. 
Polglass et al performed a cohort study to investigate a progressive CAE program with the aim of limiting muscle soreness while increasing strength. Twenty-five soccer players completed the eight week program with sessions twice a week. While there was no control group, researchers used the participants rate of perceived exertion (RPE), delayed onset muscle soreness (DOMS), and performance of the exercise to determine if the participant was able to progress to the next level in the program. The players completed the program with decreased delayed onset of muscle soreness and increased EHAD, EHAB, and EHAD:EHAB. ${ }^{22}$ (Table 3)

\section{EMG ASSESSMENT}

The study by Serner et al focused on EMG measurement of adductor longus, abdominal, and gluteal activation during eight hip adduction exercises. There were six traditional exercises which included isometric adduction with a ball between ankles, isometric adduction with a ball between knees, side-lying hip adduction, sliding hip abduction/adduction, hip adduction with an elastic band, and hip adductor machine. Two new exercises were included: CAE and supine bilateral hip adduction. The study used 40 male soccer players as the participants. When looking at EMG activity in the adductor longus, gluteus medius, external abdominal oblique, and rectus abdominis, there was a significant difference found between the three exercises (CAE, isometric adduction with ball between knees, and hip adduction with an elastic band) with the highest nEMG of the adductor longus (peak normalized EMG signal, the value was normalized using an isometric maximal voluntary contraction as a reference) activity and the three exercises with the lowest nEMG activity (isometric adduction with ball between ankles, side-lying hip adduction, supine hip adduction) of the adductor magnus. There were three exercises performed during this study that had significantly higher activation in the adductor longus muscle in the dominant leg versus the non-dominant leg. These exercises were the CAE, hip adduction with an elastic band, and side-lying hip adduction. The differences in peak nEMG of the adductor longus muscle were measured and the CAE along with isometric adduction with a ball between the knees produced a nEMG of $108 \% .{ }^{17}$ This is capable of producing a strengthening stimulus, as strength gains of active muscle are expected when EMG is greater than $40 \% .^{32}$

\section{DISCUSSION}

The purpose of this study was to systematically review the literature on the CAE and its effects on adductor muscle strength and muscle activity in athletes. After reviewing the five studies that met the inclusion criteria, the CAE significantly increased EHAD in all the studies examining EHAD, and significantly increased EHAB and EHAD:EHAB ratio in all the studies examining EHAD:EHAB ratio. The CAE also produced peak EMG of the adductor longus of $108 \%$ on the dominant leg, which was higher than other exercises which target the adductor longus. The lack of equipment needed to perform the exercise combined with the results of this systematic review suggest that the CAE is a pragmatic and viable intervention to increase adductor strength.

Research on the CAE that was used for this systematic review is subject to limitations. The small sample sizes in the included articles presents a limiting factor. Methodological procedures that introduced potential bias were 1) the fair to good ICC measurement for EMG activity in two adductor longus isometric exercises, although these were not considered to significantly influence the findings, ${ }^{17}$ 2) using the Bonferroni correction which may increase the risk of a Type 2 error, ${ }^{17}$ and 3 ) the absence of a control group in some studies which prevents definitive conclusions. Furthermore, RCTs with cluster randomization were included which increases the potential for Type 1 error due to inability to control for confounding factors. Lack of blinding to intervention type and the limited documentation of reliability and validation of the NordBord testing that may introduce potential bias are additional limitations. ${ }^{16}$

Several studies allowed players to continue their generalized strength program and therefore researchers were unable to control for all variables. Additionally, the studies excluded subjects with previous groin strain rates. Lastly, some of the research lacks reproducibility due to the nature of the EMG testing and utilization of a mean of tests in some research.

This systematic review illustrates that strength increases are associated with the CAE, however, only recently have research studies have investigated the effect of this exercise in terms of adductor injury reduction. Haroy et al randomized 35 semi-professional football (soccer) teams into an intervention group performing an adductor strengthening program based on the CAE, and a control group instructed to train as normal. After a 6-8 week preseason, the average weekly prevalence of groin problems during the season in the control group was $21.3 \%$ compared to $13.5 \%$ in the intervention group (11.7\% after removal of players not meeting the per-protocol criteria). Further analysis revealed a significant (41\%) lower risk of reporting groin injury in the intervention group. ${ }^{19}$ The same study found the average weekly prevalence of substantial groin problems in the control group was $8.0 \%$ compared to $5.7 \%$ in the intervention group (4.5\% after removal of players not meeting per-protocol criteria). These values equate to an $18 \%$ lower risk of reporting substantial groin problems; however, this was not determined to be significant. ${ }^{19}$

The effects of the CAE on injury rates remains an area in need of further research. Ishoi et al graded the evidence on various lower extremity injuries and treatments and found that mixed groin prevention programs and adductor specific groin programs showed trivial and insignificant risk reduction, and the FIFA $11+$ program showed a small but insignificant risk reduction. ${ }^{33}$ Additionally, the dosage required to achieve these strength increases while still maintaining adherence to the program presents opportunities for future research, and has been initiated by Ishoi et al who recently researched training volume and the clinical application of the CAE. ${ }^{34}$ Haroy et al found that while football (soccer) players agreed that groin injuries are prevalent in the sport, and that preventative measures should be taken, only $46 \%$ reported that they followed the CAE program as instructed, and only $31 \%$ reported that they would continue the program after the study. ${ }^{35}$ Another more recent study by van 
der Horst et all shows less adherence, with almost $70 \%$ of athletes never completing the exercise and only $4 \%$ completing it as prescribed. ${ }^{36}$ These statistics show the need to find a program that will promote adherence while maintaining the proper dosage needed for strength increases, and possibly be linked to reduced injury rates.

While there is a lack of extensive research of the CAE, the Nordic Hamstring exercise, which consists of an eccentric activation of the hamstrings, similar to the eccentric activation of the adductors during the CAE, has been researched extensively. While reviewing 40 articles that examined the effectiveness of exercise on hamstring injury prevention, Raya-Gonzalez et al noted that three studies asserted that eccentric based protocols were effective, and 17 reported that the Nordic Hamstring Exercise was effective. ${ }^{37}$ Mjolsnes et al reported an 11\% increase in eccentric hamstring strength after a 10-week Nordic Hamstring exercise program, compared to no increase in the control group completing hamstring curls. ${ }^{38}$ Furthermore, de Oliveira et al examined eccentric knee extensor and biceps femoris muscle fascicle length in female soccer players following implementation of the Nordic Hamstrings exercise, two measures also consistent with hamstrings injuries. The study by de Oliveira found that over two-thirds of participants demonstrated a significant increase in eccentric knee extensor strength and nearly half of participants demonstrated fascicle length increases. ${ }^{39}$

There is evidence that the increase in eccentric hamstring strength developed by the Nordic Hamstring exercise has been accompanied by a decrease in hamstring injuries. Van Dyk, N et al found a 0.49 reduction in risk ratio $(95 \%$ CI $0.32-0.74 ; \mathrm{p}=0.0008$ ) in programs including the Nordic Hamstring exercise. ${ }^{40} \mathrm{Al}$ Attar, WSA et al reported a significant reduction of hamstring injury risk ratio of 0.490 , equating to up to $51 \%$ reduction in hamstring strains when using the Nordic Hamstring exercise compared to no hamstring injury prevention exercise. ${ }^{41}$ Van der Horst et al conducted an RCT examining the effects of the Nordic Hamstring Exercise on injury rates in 40 football (soccer) teams. The study concluded that after 25 sessions during a 13-week training period, injury incidence rates were significantly different between intervention and control groups. The intervention group demonstrated a 0.25 (per 1,000 hours) injury incidence rates while the control group demonstrated a 0.8 injury incidence rate. However, no significant data was found on the severity of the injuries. ${ }^{42}$ Ishoi et al graded the current evidence on the Nordic Hamstring Exercise and the effects on injury rates and found that the FIFA $11+$ program coupled with the Nordic Hamstring Exercise resulted in a significant 45-65\% decreased risk of hamstrings injury in elite football (soccer) players. However, while $66 \%$ of elite football teams reported using the Nordic Hamstrings Exercise, over $80 \%$ of these teams were not compliant in the 10 -week protocol, which is likely why hamstrings injuries continue to be prevalent in football players. ${ }^{43}$ The research above cannot be directly applied to the adductor musculature due to the anatomical and kinesiological differences between muscle groups.

Additionally, this review is subject to limitations. First, there is limited research available on the CAE, therefore, only five studies are included in this systematic review. Also, the research on the CAE is not robust; only three RCTs have been conducted meeting the inclusion criteria for this systematic review. The other two studies included in the review are cohort studies. Also, the Quality Assessment Tool has only been shown to have "fair" inter-rater agreement. Lastly, all the studies included looked only at male football (soccer) players, thus reducing generalizability of the results to athletes in other sports, albeit providing an excellent data set on this population.

\section{CONCLUSION}

The results of this systematic review indicate that the $\mathrm{CAE}$ can increase adductor strength, EHAD:EHAB strength ratio, and produce EMG activity level capable of producing a strengthening stimulus in the adductors. The research examined only included male soccer players, which provides excellent data on this subgroup, while decreasing generalizability to the other populations. More research needs to be conducted to examine the relationship between the CAE and adductor injury prevention.

\section{CONFLICTS OF INTERST}

Authors have no conflicts of interest to disclose.

Submitted: February 16, 2021 CDT, Accepted: July 12, 2021 CDT 


\section{REFERENCES}

1. Eckard TG, Padua DA, Dompier TP, et al.

Epidemiology of hip flexor and hip adductor strains in National Collegiate Athletic Association athletes, 2009/2010-2014/2015. Am J Sports Med. 2017;45(12):2713-2722. doi:10.1177/03635465177161 $\underline{79}$

2. Németh G, Ohlsén H. Moment arms of hip abductor and adductor muscles measured in vivo by computed tomography. Clin Biomech. 4(3):133-136. doi:10.1016/ 0268-0033(89)90015-6

3. Hoy MG, Zajac FE, Gordon ME. A musculoskeletal model of the human lower extremity: The effect of muscle, tendon, and moment arm on the momentangle relationship of musculotendon actuators at the hip, knee, and ankle. J Biomech. 1990;23(2):157-169. $\underline{\mathrm{d}}$ oi:10.1016/0021-9290(90)90349-8

4. Kerbel YE, Smith CM, Prodromo JP, Nzeogu MI, Mulcahey MK. Epidemiology of hip and groin injuries in collegiate athletes in the United States. Orthop J Sports Med. 2018;6(5):232596711877167. doi:10.1177/ $\underline{2325967118771676}$

5. Hölmich P, Thorborg K, Dehlendorff C, Krogsgaard $\mathrm{K}$, Gluud C. Incidence and clinical presentation of groin injuries in sub-elite male soccer. Br J Sports Med. 2013;48(16):1245-1250. doi:10.1136/bjsports-20 $\underline{13-092627}$

6. Emery CA, Meeuwisse WH, Powell JW. Groin and abdominal strain injuries in the National Hockey League. Can J Sports Med. 1999;9(3):151-156. doi:10.1 $\underline{\text { 097/00042752-199907000-00006 }}$

7. Ekstrand J, Hägglund M, Waldén M. Epidemiology of muscle injuries in professional football (soccer). Am J Sports Med. 2011;39(6):1226-1232. doi:10.1177/0 363546510395879

8. Tyler TF, Nicholas SJ, Campbell RJ, McHugh MP. The association of hip strength and flexibility with the incidence of adductor muscle strains in professional ice hockey players. Am J Sports Med. 2001;29(2):124-128. doi:10.1177/03635465010290020 $\underline{301}$

9. Engebretsen AH, Myklebust G, Holme I, Engebretsen L, Bahr R. Intrinsic risk factors for acute knee injuries among male football players: A prospective cohort study. Scand J Med Sci Sports. 2010;21(5):645-652. doi:10.1111/j.1600-0838.2010.01 095.x
10. O’Connor DM. Groin injuries in professional rugby league players: A prospective study. J Sports Sci. 2004;22(7):629-636. doi:10.1080/02640410310001655 $\underline{804}$

11. Whittaker JL, Small C, Maffey L, et al. Risk factors for groin injury in sport: An updated systematic review. Br J Sports Med. 2015;49:803809.

12. Kloskowska P, Morrissey D, Small C, et al. Movement patterns and muscular function before and after onset of sports-related groin pain: A systematic review with meta-analysis. Sports Med. 2016;46:1847e1867.

13. Engebretsen AH, Myklebust G, Holme I, Engebretsen L, Bahr R. Prevention of injuries among male soccer players. Am J Sports Med. 2008;36(6):1052-1060. doi:10.1177/036354650831443 $\underline{2}$

14. Hölmich P, Larsen K, Krogsgaard K, Gluud C. Exercise program for prevention of groin pain in football players: A cluster-randomized trial. Scand J Med Sci Sports. 2009;20(6):814-821. doi:10.1111/j.160 0-0838.2009.00998.x

15. Tyler TF, Nicholas SJ, Campbell RJ, Donellan S, McHugh MP. The effectiveness of a preseason exercise program to prevent adductor muscle strains in professional ice hockey players. Am J Sports Med. 2002;30(5):680-683. doi:10.1177/03635465020300050 $\underline{801}$

16. Harøy J, Thorborg K, Serner A, et al. Including the Copenhagen Adduction Exercise in the FIFA 11+ provides missing eccentric hip adduction strength effect in male soccer players: A randomized controlled trial. Am J Sports Med. 2017;45(13):3052-3059. doi:10.1177/03635465177201 $\underline{94}$

17. Serner A, Jakobsen MD, Andersen LL, Hölmich P, Sundstrup E, Thorborg K. EMG evaluation of hip adduction exercises for soccer players: Implications for exercise selection in prevention and treatment of groin injuries. $\mathrm{Br} J$ Sports Med. 2013;48(14):1108-1114. doi:10.1136/bjsports-2012-09 $\underline{1746}$

18. Hölmich P, Uhrskou P, Ulnits L, et al. Effectiveness of active physical training as treatment for longstanding adductor-related groin pain in athletes: Randomised trial. The Lancet. 1999;353(9151):439-443. doi:10.1016/s0140-6736(9 8)03340-6 
19. Harøy J, Clarsen B, Wiger EG, et al. The Adductor Strengthening Programme prevents groin problems among male football players: A cluster-randomised controlled trial. Br J Sports Med. 2018;53(3):150-157. $\underline{\mathrm{d}}$ oi:10.1136/bjsports-2017-098937

20. Armijo-Olivo S, Stiles CR, Hagen NA, Biondo PD, Cummings GG. Assessment of study quality for systematic reviews: A comparison of the Cochrane Collaboration Risk of Bias Tool and the Effective Public Health Practice Project Quality Assessment Tool: Methodological research. J Eval Clin Pract. 2010;18(1):12-18. doi:10.1111/j.1365-2753.2010.0151 6.x

21. Ishøi L, Sørensen CN, Kaae NM, Jørgensen LB, Hölmich P, Serner A. Large eccentric strength increase using the Copenhagen Adduction Exercise in football: A randomized controlled trial. Scand J Med Sci Sports. 2016;26(11):1334-1342. doi:10.1111/sms.1 $\underline{2585}$

22. Polglass G, Burrows A, Willett M. Impact of a modified progressive Copenhagen Adduction Exercise programme on hip adduction strength and postexercise muscle soreness in professional footballers. BMJ Open Sport Exerc Med. 2019;5(1):20000570. doi:10.1136/bmjsem-2019-0005 $\underline{70}$

23. Kohavi B, Beato M, Laver L, Freitas TT, Chung LH, Dello Iacono A. Effectiveness of field-based resistance training protocols on hip muscle strength among young elite football players. Can J Sports Med. 2018;(1). doi:10.1097/jsm.0000000000000649

24. Thorborg K, Couppé C, Petersen J, Magnusson SP, Holmich P. Eccentric hip adduction and abduction strength in elite soccer players and matched controls: A cross-sectional study. Br J Sports Med. 2011;45(1):10-13. doi:10.1136/bjsm.2009.061762

25. Claiborne TL, Timmons MK, Pincivero DM. Test-retest reliability of cardinal plane isokinetic hip torque and EMG. J Electromyogr Kinesiol. 2009;19(5):e345-e352. doi:10.1016/j.jelekin.2008.07.0 $\underline{05}$

26. Aminaka N, Pietrosimone BG, Armstrong CW, Meszaros A, Gribble PA. Patellofemoral pain syndrome alters neuromuscular control and kinetics during stair ambulation. J Electromyogr Kinesiol. 2011;21(4):645-651. doi:10.1016/j.jelekin.2011.03.007

27. Merletti R, Hermens H. Introduction to the special issue on the SENIAM European Concerted Action. J Electromyogr Kinesiol. 2000;10(5):283-286. doi:10.101 6/s1050-6411(00)00019-5
28. Bolgla LA, Uhl TL. Reliability of electromyographic normalization methods for evaluating the hip musculature. J Electromyogr Kinesiol. 2007;17(1):102-111. doi:10.1016/j.jelekin.20 05.11 .007

29. Hodges PW, Richardson CA. Contraction of the abdominal muscles associated with movement of the lower limb. Phys Ther. 1997;77(2):132-142; discussion 142-4. doi:10.1093/ptj/77.2.132

30. Anders C, Wagner H, Puta C, Grassme R, Petrovitch A, Scholle H-C. Trunk muscle activation patterns during walking at different speeds. $J$ Electromyogr Kinesiol . 2007;17(2):245-252. doi:10.101 6/j.jelekin.2006.01.002

31. Barton CJ, Coyle JA, Tinley P. The effect of heel lifts on trunk muscle activation during gait: A study of young healthy females. J Electromyogr Kinesiol. 2009;19(4):598-606. doi:10.1016/j.jelekin.2008.03.001

32. Reiman MP, Bolgla LA, Loudon JK. A literature review of studies evaluating gluteus maximus and gluteus medius activation during rehabilitation exercises. Physiother Theory Pract. 2011;28(4):257-268. doi:10.3109/09593985.2011.6049 $\underline{81}$

33. Ishøi L, Krommes K, Husted RS, Juhl CB, Thorborg K. Diagnosis, prevention and treatment of common lower extremity muscle injuries in sport - grading the evidence: A statement paper commissioned by the Danish Society of Sports Physical Therapy (DSSF). $\mathrm{Br} \mathrm{J}$ Sports Med. 2020;54(9):528-537. doi:10.1136/bjsport s-2019-101228

34. Ishøi L, Thorborg K. Copenhagen adduction exercise can increase eccentric strength and mitigate the risk of groin problems: But how much is enough! Br J Sports Med. 2021. doi:10.1136/bjsports-2020-103 $\underline{564}$

35. Harøy J, Wiger EG, Bahr R, Andersen TE. Implementation of the Adductor Strengthening Programme: Players primed for adoption but reluctant to maintain - A cross - sectional study. Scand J Med Sci Sports. 2019;29(8):1092-1100. doi:1 $\underline{0.1111 / \mathrm{sms} .13444}$

36. van der Horst N, van de Hoef S, van Otterloo $P$, Klein M, Brink M, Backx F. Effective but not adhered to: How can we improve adherence to evidence-based hamstring injury prevention in amateur football? Can J Sports Med. 2018;Publish Ahead of Print. doi:10.109 7/jsm.0000000000000710

37. Raya-Gonzalez J, Castillo D, Clemente FM. Injury prevention of hamstring injuries through exercise interventions: An umbrella review. J Sports Med Phys Fit. 2021. doi:10.23736/S0022-4707.21.11670-6 
38. Mjolsnes R, Arnason A, Osthagen T, et al. A 10 -week randomized trial comparing eccentric vs. concentric hamstring strength training in welltrained soccer players. Scand J Med Sci Sports. 2004;14(5):311-317. doi:10.1046/j.1600-0838.2003.36 7.x

39. de Oliveira NT, Medeiros TM, Vianna KB, Oliveira G dos S, de Araujo Ribeiro-Alvares JB, Baroni BM. A four-week training program with the Nordic hamstring exercise during preseason increases eccentric strength of male soccer players. Int J Sports Phys Ther. 2020;15(4):571-578. doi:10.26603/ijspt202 $\underline{00571}$

40. van Dyk N, Behan FP, Whiteley R. Including the Nordic hamstring exercise in injury prevention programmes halves the rate of hamstring injuries: A systematic review and meta-analysis of 8459 athletes. Br J Sports Med. 2019;53(21):1362-1370. doi:10.1136/ bjsports-2018-100045
41. Al Attar WSA, Soomro N, Sinclair PJ, et al. Effect of injury prevention programs that include the Nordic hamstring exercise on hamstring injury rates in soccer players: A systematic review and metaanalysis. J Sci Med Sport. 2017;20:e45. doi:10.1016/j.js ams.2017.01.24

42. van der Horst N, Smits D-W, Petersen J, Goedhart EA, Backx FJG. The preventive effect of the Nordic Hamstring Exercise on hamstring injuries in amateur soccer players. Am J Sports Med. 2015;43(6):1316-1323. doi:10.1177/036354651557405 7

43. Ishøi L, Krommes K, Husted RS, Juhl CB, Thorborg K. Diagnosis, prevention and treatment of common lower extremity muscle injuries in sport - grading the evidence: A statement paper commissioned by the Danish Society of Sports Physical Therapy (DSSF). $\mathrm{Br} \mathrm{J}$ Sports Med. 2020;54(9):528-537. doi:10.1136/bjsport s-2019-101228 